Keywords: Example keywords

Retention: Permanent

\title{
Thermal and Spectroscopic Analyses of Next Generation Caustic Side Solvent Extraction Solvent (CSSX) Contacted with 3, 8, and 16 Molar Nitric Acid
}

F. F. Fondeur

S. D. Fink

September 30, 2011

Savannah River National Laboratory

Savannah River Nuclear Solutions, LLC

Aiken, SC 29808

Prepared for the U.S. Department of Energy under contract number DE-AC09-08SR22470.

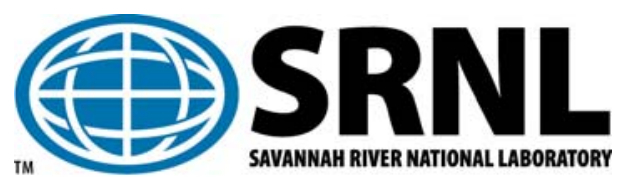


SRNL-STI-2011-00576

Revision 0

\section{DISCLAIMER}

This work was prepared under an agreement with and funded by the U.S. Government. Neither the U.S. Government or its employees, nor any of its contractors, subcontractors or their employees, makes any express or implied:

1. warranty or assumes any legal liability for the accuracy, completeness, or for the use or results of such use of any information, product, or process disclosed; or

2. representation that such use or results of such use would not infringe privately owned rights; or

3. endorsement or recommendation of any specifically identified commercial product, process, or service.

Any views and opinions of authors expressed in this work do not necessarily state or reflect those of the United States Government, or its contractors, or subcontractors.

\section{Printed in the United States of America \\ Prepared for \\ U.S. Department of Energy}




\section{REVIEWS AND APPROVALS}

AUTHORS:

F.F. Fondeur, Separations and Actinide Science Programs

Date

TECHNICAL REVIEW:

D. T. Hobbs, Separations and Actinide Science Programs

Date

APPROVAL:

S.D. Fink, Manager and Co-author

Date

Separations and Actinide Science Programs

S.L. Marra, Manager

Date

Environmental \& Chemical Process Technology Research Programs

B.A. Oard, Manager

Date

MCU Life Extension/NGS

J. E. Occhipinti,

Date

SRR Engineering 


\section{EXECUTIVE SUMMARY}

A new solvent system referred to as Next Generation Solvent or NGS, has been developed at Oak Ridge National Laboratory for the removal of cesium from alkaline solutions in the Caustic Side Solvent Extraction process. NGS is proposed for deployment at MCU and at the Salt Waste Processing Facility. This work investigated the chemical compatibility between NGS and $16 \mathrm{M}$, $8 \mathrm{M}$, and $3 \mathrm{M}$ nitric acid from contact that may occur in handling of analytical samples from MCU or, for $3 \mathrm{M}$ acid, which may occur during contactor cleaning operations at MCU.

This work shows that reactions occurred between NGS components and the high molarity nitric acid. In the case of $16 \mathrm{M}$ and $8 \mathrm{M}$ nitric acid, initially organo-nitrate groups are generated and attach to the modifier and that with time oxidation reactions convert the modifier into a tarry substance with gases $\left(\mathrm{NO}_{\mathrm{x}}\right.$ and possibly $\left.\mathrm{CO}\right)$ evolving. Calorimetric analysis of the organonitrate revealed the reaction products are not explosive nor will they deflagrate.

NGS exposure to $3 \mathrm{M}$ nitric acid resulted in much slower reaction kinetics and that the generated products were not energetic.

We recommended conducting Accelerated Rate calorimetry on the materials generated in the $16 \mathrm{M}$ and $8 \mathrm{M}$ nitric acid test. Also, we recommend continue monitoring of the samples contacting NGS with $3 \mathrm{M}$ nitric acid. 


\section{TABLE OF CONTENTS}

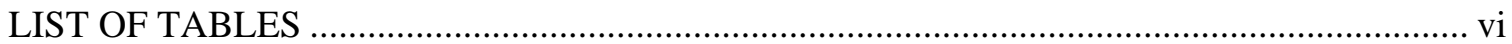

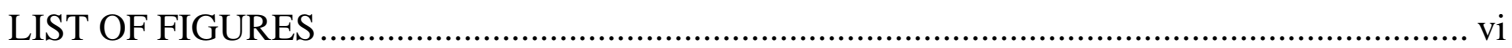

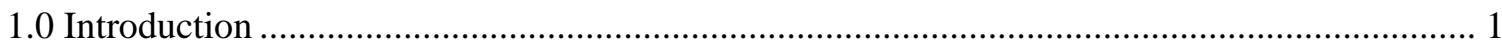

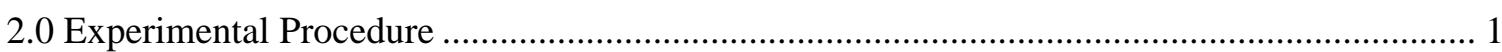

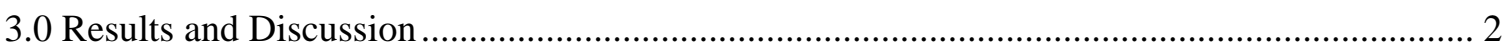

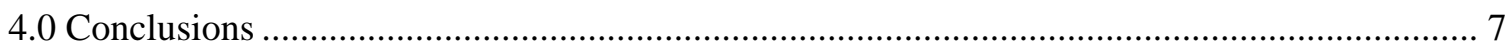

5.0 Recommendations, Path Forward or Future Work ….............................................................. 7

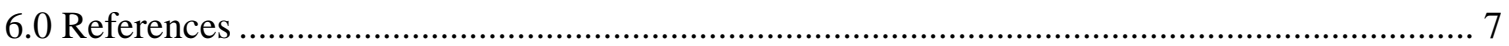




\section{LIST OF TABLES}

Table 1. Component composition of NGS .2

\section{LIST OF FIGURES}

Figure 3.1. A typical breakdown of the histogram into the layers that make the picture. The mode of each peak was used to determine the color intensity with time. Also included a line profile for estimating thickness of each layer..

Fig. 3.2 The FTIR spectrum of the NGS components for identification in the subsequent figures.4

Fig. 3.3 The enthalpy of decomposition of energetic (explosive) materials....................4

Fig. 3.4. A typical evolution in the chemical reaction between NGS and $16 \mathrm{M}$ nitric acid........8

Fig. 3.5 A plot of the histogram mode for both aqueous (16 M nitric acid) and organic layer

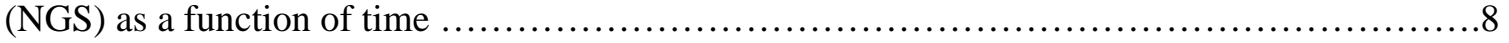

Figure 3.6. The energetic and chemistry of NGS after 4.5 hours in $16 \mathrm{M}$ nitric acid..............9

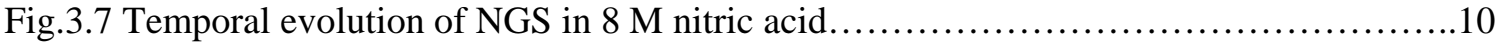

Fig. 3.8 The temporal evolution of the histogram mode for both aqueous (8 $\mathrm{M}$ nitric acid) and

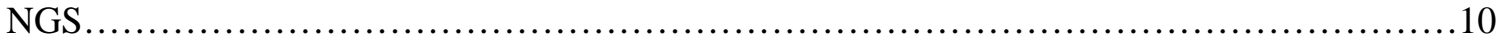

Fig. 3.9 The energetic and chemistry of NGS after 120 hours in $8 \mathrm{M}$ nitric acid................11

Fig. 3.10 The temporal evolution of NGS in 3 M nitric acid..............................12

Fig. 3.11 The energetic and chemistry of NGS after 48 hours in $3 \mathrm{M}$ nitric acid.................13

Fig. 3.12 The physical appearance of NGS after 288 hours in $16 \mathrm{M}, 8 \mathrm{M}$ and $3 \mathrm{M}$ nitric (note the lower liquid level at higher nitric acid concentration)....................................14 


\section{LIST OF ABBREVIATIONS}

\begin{tabular}{|c|c|}
\hline $\begin{array}{l}\text { Cs-7SB } \\
\text { (or modifier) }\end{array}$ & 1-(2,2,3,3-tetrafluoropropoxy)-3-(4-sec-butylphenoxy)-2-propanol \\
\hline CSSX & Caustic-Side Solvent Extraction \\
\hline DCiTDG & $\begin{array}{l}N, N \text { '-dicyclohexyl-N”-isotridecylguanidine, marketed by Cognis as } \\
\text { Lix®79 }\end{array}$ \\
\hline $\mathrm{D}_{\mathrm{Cs}}$ & distribution ratio for cesium \\
\hline $\mathrm{DF}$ & decontamination factor \\
\hline DSC & differential scanning calorimetry \\
\hline FTIR & Fourier transform infrared spectroscopy \\
\hline HPLC & High Performance Liquid Chromatography \\
\hline MaxCalix & 1,3-alt-25,27-Bis(3,7-dimethyloctyloxy) calix[4]arene-benzocrown-6 \\
\hline MCU & Modular Caustic-Side Solvent Extraction Unit \\
\hline NGS & Next Generation Solvent \\
\hline ORNL & Oak Ridge National Laboratory \\
\hline SRNL & Savannah River National Laboratory \\
\hline SRS & Savannah River Site \\
\hline SVOA & Semi-volatile Organic Analysis \\
\hline
\end{tabular}




\subsection{Introduction}

A solvent extraction system for removal of cesium from alkaline solutions was developed utilizing a novel solvent invented at the Oak Ridge National Laboratory (ORNL). ${ }^{1}$ This solvent consists of a calix[4]arene-crown-6 extractant dissolved in an inert hydrocarbon matrix. A modifier is added to the solvent to enhance the extraction power of the calixarene and to prevent the formation of a third phase. An additional additive is used to improve stripping performance and to mitigate the effects of any surfactants present in the feed stream. The process that deploys this solvent system is known as Caustic Side Solvent Extraction (CSSX). The solvent system has been deployed at the Savannah River Site (SRS) in the Modular CSSX Unit (MCU) since 2008.

The MCU uses centrifugal contactors (10-in for extraction stages and 5-in for scrub and strip stages) to provide mechanical mixing and phase separation between the solvent and alkaline waste solutions by way of two separations. The first separation extracts cesium from the waste solutions into the solvent system; the second separation strips the cesium from the solvent system while providing a nominal cesium concentration factor of 15 . From its radioactive start-up in April 2008 until the end of August 2011, MCU processed approximately 2 million gallons of HLW solution for disposition. The decontaminated salt solution is sent to the SRS Saltstone Production Facility and the concentrated cesium stream is transferred to Defense Waste Processing Facility.

Subsequent development efforts by ORNL have identified an improved solvent system that can raise the expected decontamination factor (DF) in MCU from 200 to more than $40,000{ }^{2}$ The improved DF is attributed to an increased distribution ratio for cesium $\left(\mathrm{D}_{\mathrm{Cs}}\right)$ in extraction from $\sim 15$ to $\sim 60$, an increased solubility of the calixarene in the solvent from $0.007 \mathrm{M}$ to $0.050 \mathrm{M}$, and use of boric acid $\left(\mathrm{H}_{3} \mathrm{BO}_{3}\right)$ stripping that yields $\mathrm{D}_{\mathrm{Cs}}$ values less than 0.01 . The improved solvent system contains four components: 1) $0.050 \mathrm{M}$ 1,3-alt-25,27-Bis(3,7-dimethyloctyloxy) calix[4]arene-benzocrown-6, also known as MaxCalix, is the extractant; 2) $0.50 \mathrm{M} \mathrm{1-(2,2,3,3-}$ tetrafluoropropoxy)-3-(4-sec-butylphenoxy)-2-propanol, or Cs-7SB, is the modifier; 3) $0.003 \mathrm{M}$ $N, N$ '-dicyclohexyl-N"-isotridecylguanidine, or DCiTDG, is the suppressor; and 4) $\mathrm{C}_{12}$-isoparaffinic hydrocarbon, or Isopar ${ }^{\circledR} \mathrm{L}$, is the diluent. The modified solvent system is referred to as the Next Generation Solvent (NGS).

During MCU and Salt Waste Processing Facility operations, unexpected shut downs and planned shut downs for maintenance will occur. Periodically during operations, salts will deposit in the contactors requiring cleaning the units. The flushing operation for cleaning the centrifugal contactors will use $3 \mathrm{M}$ nitric acid. Contacting with more concentrated acids (e.g., $3 \mathrm{M}$ ) may also prove beneficial for deposits that dissolve slowly in the $1 \mathrm{M}$ acid. Also, processing samples from MCU in F/H Labs involves the potential risk of inadvertent disposal of residual solvent to the drain system or contact with concentrated (16M) nitric acid. For the baseline solvent, prior studies assessed the reaction rates of the solvent with various concentrations of nitric acid., ${ }^{3,4}$ Savannah River National Laboratory (SRNL) conducted similar tests with the new solvent contacting 3, 8, and $16 \mathrm{M}$ to provide analogous safety bases data. ${ }^{6,7}$

\subsection{Experimental Procedure}

Personnel took $20 \mathrm{~mL}$ of NGS (whose composition is shown in Table 1) and $40 \mathrm{~mL}$ of either $16 \mathrm{M}, 8 \mathrm{M}$, or $3 \mathrm{M}$ nitric acid and placed the two liquids in a $60 \mathrm{~mL}$ bottle (Teflon ${ }^{\mathrm{TM}}$ capped containing a $2 \mathrm{~mm}$ hole for gas release). The bilayer configuration (no mixing) represents likely scenarios during sampling disposal to waste drains or stagnant cleaning periods in the contactors. 
Two samples per each nitric acid concentration were prepared: one sample was used for visual tracking with time (photographs) and the other sample was used to provide samples of "physically" distinguishable layers for chemical analysis (by Fourier transform infrared spectroscopy, FTIR) and energetic screening by Differential Scanning Calorimetry (DSC). Some samples were submitted for Semi-volatile Organic Analysis (SVOA) and High Performance Liquid Chromatography (HPLC) analysis (from the NGS layer). The amount of sample removed from each testing bottle was approximately $0.5 \mathrm{~mL}$ (to ensure enough liquid remained for future testing). The small liquid samples (removed for analysis) were placed in $2 \mathrm{~mL}$ glass bottles (sized to avoid a large overhead that may change the composition of the removed liquid). Testing begun at 08:10 on 14 September 2011 and this time is considered "time zero" for this test.

FTIR of the samples was conducted with a Nicolet Nexus 670 instrument using a single bounce attenuated reflectance diamond crystal. More than 100 scans were collected at a resolution of 4 $\mathrm{cm}^{-1}$ to obtain signal to noise ratios greater than 340 .

DSC was conducted with Perkin Elmer PE7 instrument. Approximately $7.4 \mathrm{mg}$ of sample was placed in gold crucible that was covered with a gold lid (loosely placed over the cup) and then heated at $20^{\circ} \mathrm{C}$ per min. The lid was in placed on gold cup to minimize liquid splashing out of the cup, however, the lid was not sealed, which allowed gas release.

Table 1. Component composition of Next Generation Solvent

\begin{tabular}{|l|l|}
\hline Component & \multicolumn{1}{|c|}{$\begin{array}{c}\text { Next Generation Solvent } \\
\text { concentration }\end{array}$} \\
\hline Modifier & $\begin{array}{l}\text { Linear/branched } \\
\text { alkanes }\end{array}$ \\
\hline Isopar ${ }^{\circledR} \mathrm{L}$ & 21 wt \% \\
\hline $\begin{array}{l}\text { MaxCalix } \\
\text { Cognis) }\end{array}$ & (from
\end{tabular}

\subsection{Results and Discussion}

Personnel analyzed the optical pictures using Image ${ }^{*}$ software to obtain both histogram and line profile to determine the width of the different layers in the bottles (as shown in Figure 3.1). The

\footnotetext{
* ImageJ is the public domain software "Image Processing and Analysis in JAVA" available via the National Institute of Health.
} 
histogram was used to determine the color intensity in a given layer. When two or more colors were present in a layer the histogram will show numerous (some overlapping with each other). The mode of each peak was registered and used to determine the color of that layer. A typical image analysis is shown in Fig. 3.1 where a multimode histogram was de-convoluted into single peaks belonging to the different layers in a sample (in this case NGS in $16 \mathrm{M}$ nitric acid). The peak mode for both the organic (top layer) and aqueous layer (bottom layer) and sometimes the interfacial layer was recorded as a function of time.
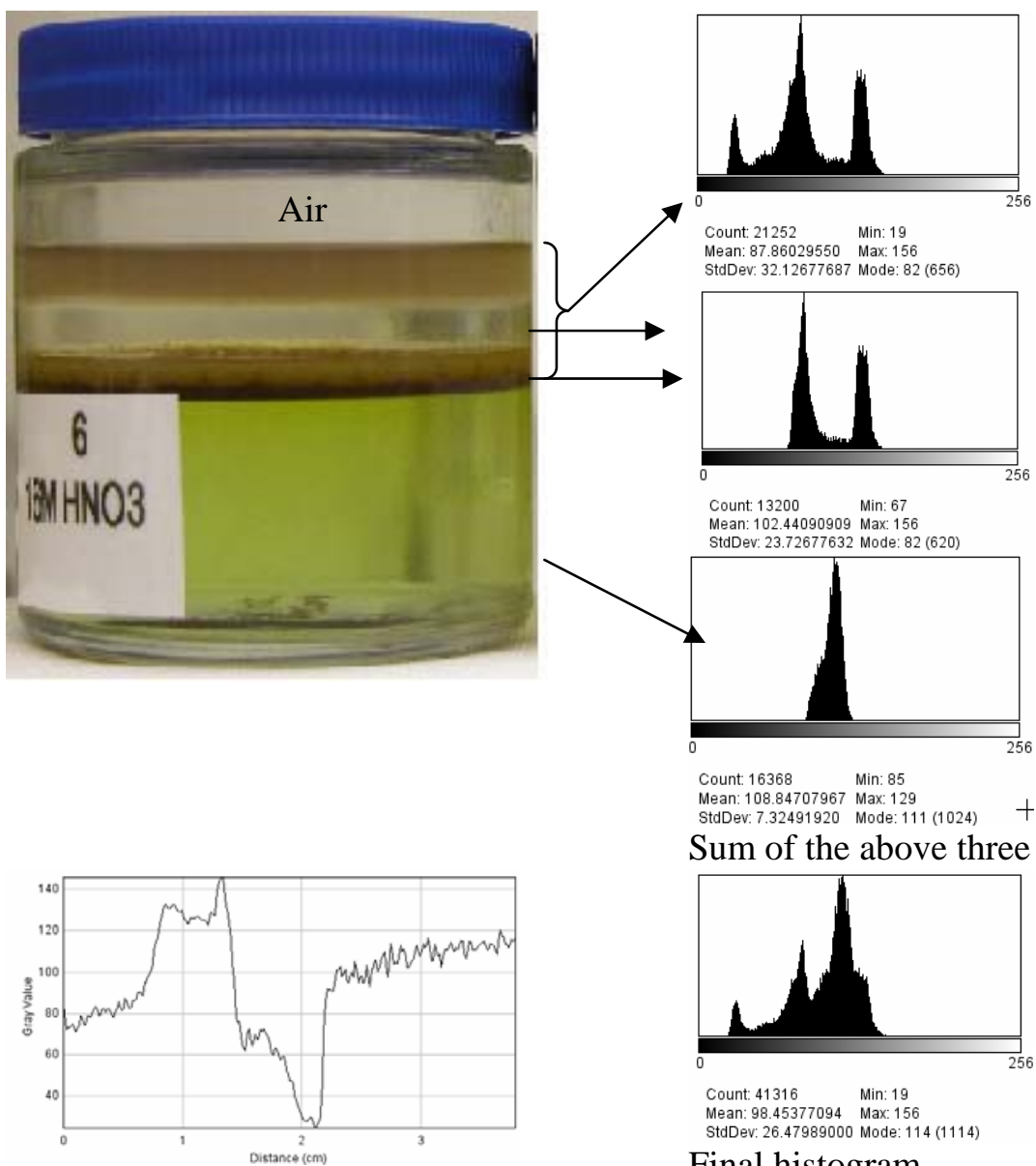

Line profile from the top brown layer down

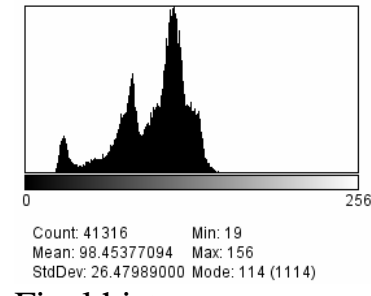

to aqueous layer (green)

Figure 3.1. A typical breakdown of the histogram into the layers visible in a digital image. The mode of each peak was used to determine the color intensity with time. Also included is a line profile for estimating thickness of each layer.

Personnel also analyzed the different layers by FTIR. To train the reader to read the FTIR data, Figure 3.2 shows the FTIR spectrum of each of the four components in NGS. As can be seen from Fig. 3.2 each NGS component has a unique absorption peak that can be used for identification. In the case of nitration, nitro-alkanes have a unique peak in the $1601-1531 \mathrm{~cm}^{-1}$ region (1381-1310 cm-1 for the asymmetric stretching) while the nitro-aromatics have a unique peak at $1587-1555 \mathrm{~cm}-1$ (1357-1318 for the asymmetric stretching) ${ }^{9}$ Exothermic reactions in the DSC were evaluated against reported enthalpy of explosives in Fig. 3.3. 


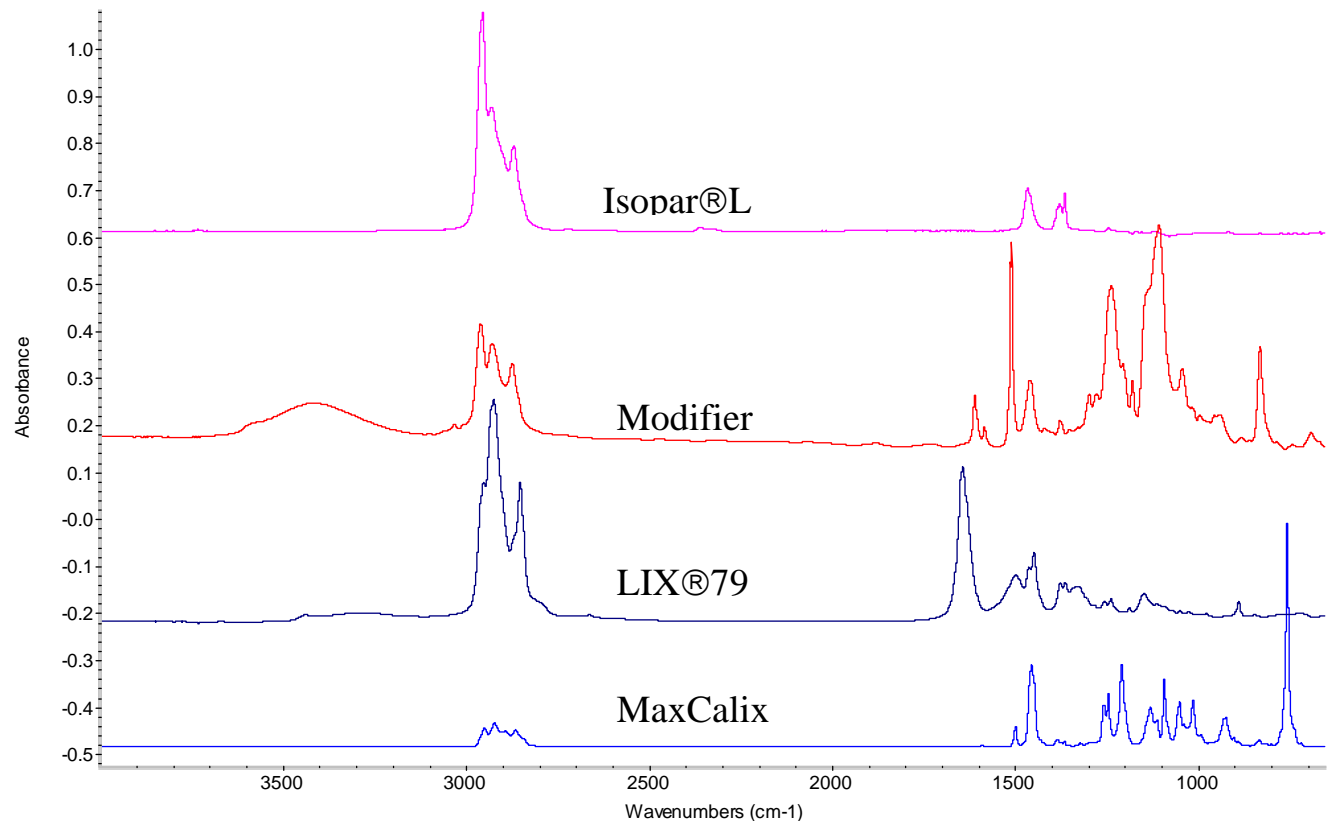

Fig. 3.2 The FTIR spectrum of the NGS components for identification in the subsequent figures.

Thermal stability of nitrocompounds

\begin{tabular}{llll}
\hline Compounds & $T_{\text {onset }}\left({ }^{\circ} \mathrm{C}\right)$ & $-\Delta H\left(\mathrm{Jg}^{-1}\right)$ & $-\Delta H\left(\mathrm{~kJ} \mathrm{~mol} \mathrm{NO}{ }_{2}^{-1}\right)$ \\
\hline Ammonium nitrate & 250 & 1577 & 126 \\
Nitrobenzene & 380 & 2757 & 339 \\
Nitromethane & 320 & 5292 & 323 \\
2-Nitrophenol & 250 & 2481 & 345 \\
3-Nitrophenol & 310 & 2269 & 316 \\
4-Nitrophenol & 270 & 2155 & 300 \\
2-Nitrotoluene & 290 & 2404 & 329 \\
3-Nitrotoluene & 310 & 2070 & 284 \\
4-Nitrotoluene & 320 & 2322 & 318 \\
2-Nitroaniline & 280 & 2225 & 307 \\
3-Nitroaniline & 300 & 2269 & 314 \\
4-Nitroaniline & 310 & 2026 & 279 \\
2-Nitrobenzoic acid & 270 & 1894 & 297 \\
3-Nitrobenzoic acid & 300 & 1899 & 298 \\
4-Nitrobenzoic acid & 310 & 1934 & 304 \\
1,2-Dinitrobenzene & 280 & 3310 & 259 \\
1,3-Dinitrobenzene & 270 & 3488 & 293 \\
1,4-Dinitrobenzene & 350 & 3701 & 311 \\
2,4-Dinitrotoluene & 250 & 3574 & 298 \\
3,4-Dinitrotoluene & 280 & 3987 & 333 \\
2,6-Dinitrotoluene & 290 & 3451 & 288 \\
1-Chloro-4-nitrobenzene & 395 & 2283 & 360 \\
2,4-Dinitrophenol & 240 & 3598 & 331 \\
2,4,6-Trinitrophenol & 220 & 5130 & 391 \\
\hline
\end{tabular}

$T_{\text {onset }}$ : onset temperature; $\Delta H$ : enthalpy change.

Fig. 3.3 The enthalpy of decomposition of energetic (explosive) materials (from Y. S. Duh, C. Lee, C. C. Hsu, D. R. Hwang, and C. S. Kao, "Chemical Incompatibility of Nitrocompounds,” Journal of Hazardous Materials, 53 (1997), 183-194). 


\section{NGS in 16 M Nitric Acid}

We observed that components of the NGS immediately react with 16M nitric acid as evidenced by the development of highly colored regions at the organic/aqueous interface and the aqueous phase. Fig. 3.4 shows a series of pictures taken after 2, 4.5 and 6 hours of contact. A plot of the mode for both the aqueous and organic layer as a function of time is shown in Fig. 3.5. As can be seen in Fig. 3.5, the pixel value for the aqueous layer decreased rapidly initially, remains constant for about 2 hours and the begins to decrease again. This behavior suggest at least two different diffusions into (or out of) the aqueous layer. However, the data at 14:12 hours is suspect since $\mathrm{NO}_{\mathrm{x}}$ gas was generated that influenced the color in the aqueous. In contrast, the histogram mode for the organic layer exhibits a small increase during the first 90 minutes followed by a rapid decrease over the next five hours. Indicating a possible single phenomenon occurred (again the data at 14:12 is suspect due $\mathrm{NO}_{\mathrm{x}}$ ). For example, a steady diffusion and reaction of components in or out of the organic layer may give a steady color change. Also note that the color from the aqueous did not add into the color of the organic as one may expect from a multiple scattering sample (for example the light from the aqueous layer travels in every direction and some of that light hits the organic layer thereby adding to the color of the organic layer but the magnitude of that effect is not significant in this situation).

Results from spectroscopic and calorimetric analysis of samples taken from the upper organic phase, the highly colored interfacial region, and the lower aqueous phase are shown in Fig. 3.6 (after 4.5 hours of exposure). The upper organic layer is mostly Isopar ${ }^{\circledR} \mathrm{L}$ with a small amount of nitrated modifier $\left(1528 \mathrm{~cm}^{-1}\right)$. The modifier, guanidine derivative, and MaxCalix reacted immediately with $16 \mathrm{M}$ nitric acid leaving behind Isopar ${ }^{\circledR} \mathrm{L}$. This is the expected trend since the hydrocarbon diluent, Isopar®L would be the least reactive organic component in the solvent system. On the other hand, solvent components with aromatic groups and hydroxyls (alcohols) are more susceptible to nitration and oxidation. Both the modifier and the MaxCalix contain aromatic groups. Also, the guanidine suppressor contains an amine group with pKa value of 10 that readily ionizes and partitions to the aqueous phase. ${ }^{10}$ The organic compounds formed upon reaction of the extractant, modifier and suppressor with nitric acid are much more polar and dense and would be expected to diffuse into the aqueous solution resulting in a separation from Isopar ${ }^{\circledR} \mathrm{L}$. The remaining organic layer gave an exothermic peak of $-10.17 \mathrm{~J} / \mathrm{g}$ indicating residual nitrated modifier in that layer.

The lower aqueous layer had a high concentration of organic (mostly reacted modifier). The organics in the aqueous layer did not decompose energetically as noted by the absence of an exothermic peak in the DSC plot and the absence of a organo-nitro peak (at $1530 \mathrm{~cm}^{-1}$ ) in the FTIR spectra. However, the peak and 1620 and $1280 \mathrm{~cm}^{-1}$ could be due to a trinitroxy propane like molecule but since no energetic was detected in the DSC test, this molecule has no impact on this system (an ARC test of this layer may provide further evidence of the lack of energy seen by the DSC). Please note that the large endothermic peak in the DSC figure is due to water boiling from the aqueous layer and that boiling process did not steam-strip the organic from the sample since the baseline in the DSC curve was nearly restored to the values before the evaporation (for a large evaporation or mass loss, the baseline is always higher in value after the event).

The interface between the organic and aqueous layer was intensely colored and consisted mostly nitrated organic as evidenced by the presence of strong bands around 1560, 1526 and $1341 \mathrm{~cm}^{-1}$ which are indicated of organo-nitro groups. The DSC analysis indicated a large and broad exothermic peak with a exothermic energy of $-605 \mathrm{~J} / \mathrm{g}$. This energy is well below the lower 
bound energy of $1000 \mathrm{~J} / \mathrm{g}$ (see Figure 3.3). The exothermic decomposition is broad enough that the reaction does not meet the definition of a deflagration reaction. ${ }^{11}$

\section{NGS in 8 M Nitric Acid}

A series of pictures and sample removal was performed on the sample containing NGS and $8 \mathrm{M}$ nitric acid. A characteristic set of pictures is shown in Fig. 3.7. A similar image analysis exercise was conducted on these images. The mode associated with the aqueous and organic layer was recorded (from the multimode histogram). As can be seen in Fig. 3.8, the organic layer proceeded steadily from its initial yellow color to the red color (an S-shaped curve resembling that of diffusion was observed) while the aqueous layer remained nearly transparent during this time; there was a "yellow" colored front moving into the aqueous layer. Since measuring the diffusion front (by Fick's diffusion) is not an objective in this task, this front speed is not reported here although the data exist. This visual behavior is an indication that the type of reactions and their kinetics are different from those observed in the $16 \mathrm{M}$ nitric acid tests.

A spectroscopic and calorimetric analysis of the sample (NGS in $8 \mathrm{M}$ nitric acid) is shown in Fig. 3.9. As can be seen from Fig. 3.9, the organic layer is mostly the unreacted modifier containing a smaller concentration of Isopar ${ }^{\circledR L}$ and an even smaller concentration of reacted modifier that contains little organo-nitro groups (as indicated by the small peak at $1560 \mathrm{~cm}^{-1}$ in the FTIR spectrum) after 120 hours of contact with $8 \mathrm{M}$ nitric acid. The corresponding calorimetric scan indicates a very weak and broad exotherm near $167^{\circ} \mathrm{C}$ with an enthalpy value of $-7.1 \mathrm{~J} / \mathrm{g}$. In this case it is possible that the nitric acid migrated into the organic layer and reacted with the modifier and the heat from that reaction may have evaporated Isopar ${ }^{\circledR}$ L.

Similarly, the aqueous layer contains a small amount of organic that upon heating in the DSC generated a very small and broad exotherm near $160{ }^{\circ} \mathrm{C}$ right after water boiled from the sample. Again, indicating the absence of energetic material in this layer.

Samples from the interface were collected but the analysis from those samples are not available for this report, but will be reported in a future report.

\section{NGS in 3 M Nitric Acid}

Figures 3.10 and 3.11 show the color evolution (due to reaction), spectroscopic identification and calorimetric behavior of NGS and $3 \mathrm{M}$ nitric acid. The data from the histogram analysis was not available for this report but from Fig. 3.10, the organic layer from the 16 September 2011 picture show less color intensity (and more transparency) than the color seen in the 14 September and 26 September 2011 pictures. This may indicate a possible change in lighting condition when the 14 September 2011 picture was taken. The histogram analysis of the picture will be reported in a later report. The spectroscopic and calorimetric analysis (Fig. 3.11) of this sample after 48 hours of exposure indicates that neither the organic layer nor the aqueous layer has changed significantly. This indicates a much slower reaction and that longer time is required to detect changes with these instruments. In fact, Fig. 3.12 shows NGS in $16 \mathrm{M}, 8 \mathrm{M}$ and $3 \mathrm{M}$ nitric acid 288 hours after the test and from this picture it can be seen that the NGS layer in the $3 \mathrm{M}$ nitric acid sample, a yellow colored front is moving through the NGS layer. Also note that the interface between NGS and the $8 \mathrm{M}$ nitric acid sample has darkened and thickened (possibly indicating a new byproduct from a reaction). Liquid from these samples were removed and will be analyzed and reported later. 


\subsection{Conclusions}

A new solvent system referred to as Next Generation Solvent or NGS, has been developed at Oak Ridge National Laboratory for the removal of cesium from alkaline solutions in the Caustic Side Solvent Extraction process. This work investigated the chemical compatibility between NGS and $16 \mathrm{M}, 8 \mathrm{M}$, and $3 \mathrm{M}$ nitric acid typically used throughout the operations and analysis of MCU solvent.

NGS components readily react with $16 \mathrm{M}$ and $8 \mathrm{M}$ nitric acid solutions. In the case of $16 \mathrm{M}$ and 8 $\mathrm{M}$ nitric acid, initially organo-nitrate groups are generated and attach to the modifier and that with time oxidation reactions turns the organic into a tarry substance with gases $\left(\mathrm{NO}_{\mathrm{x}}\right.$ and possibly $\mathrm{CO})$ evolved. Calorimetric analysis of the organo-nitrate revealed these materials are not explosive nor will they deflagrate.

NGS exposure to $3 \mathrm{M}$ nitric acid resulted in much slower reaction kinetics and that the generated products were not energetic.

We recommend conducting Accelerated Rate calorimetry on the materials generated in the $8 \mathrm{M}$ nitric acid test.

\subsection{Recommendations, Path Forward or Future Work}

We recommend conducting Accelerate Rate calorimetry of the material generated in the $8 \mathrm{M}$ nitric acid test. Also to analyze the aqueous layer from the $16 \mathrm{M}$ and $8 \mathrm{M}$ test for IC Anions (fluorides). We also recommend continued testing of the $3 \mathrm{M}$ acid sample.

\subsection{References}

${ }^{* 1}$ P. V. Bonnensen, et al., "Alkaline-Side Extraction of Cesium from Savannah River Tank Waste Using a Calixarene-Crown Ether Extractant," ORNL/TM-13704 (1998).

${ }^{* 2}$ B. A. Moyer, P. V. Bonnesen, L. H. Delmau, F. V. Sloop, Jr., N. J. Williams, J. F. Birdwell, Jr., D. L. Lee, R. A. Leonard, S. D. Fink, T. B. Peters, and M. W. Geeting, "Development of the Next-Generation Caustic-Side Solvent Extraction (NG-CSSX) Process for Cesium Removal from High-Level Tank Waste,” Paper 11346, Proc. Waste Management 2011, February 27-March 3, 2011, Phoenix, AZ; Waste Management Symposia, Tempe, AZ (2011).

${ }^{* 3}$ P. V. Bonnesen, F. V. Sloop, Jr., and N. L. Engle, "Stability of the Caustic-Side Solvent Extraction (CSSX) Process Solvent: Effect of High Nitrite on Solvent Nitration,” ORNL/TM-2002/115, July 2002.

${ }^{*}$ F. F. Fondeur, D. T. Hobbs and S. D. Fink, "Thermal and Spectroscopic Analyses of Caustic-Side Solvent Extraction Solvent Contacted with 16 Molar and 8 Molar Nitric Acid,” WSRC-TR-2007-00212, July 12, 2007.

${ }^{*}$ F. F. Fondeur, D. T. Hobbs and S. D. Fink, "Thermal and Spectroscopic Analyses of Caustic-Side Solvent Extraction Solvent Contacted with 1 Molar and 3 Molar Nitric Acid,” WSRC-STI-2007-00385, July 23, 2007.

${ }^{* 6}$ M. Desphpande, “NGS/mMST Studies at ARP/MCU,” TTR-WPT-2010-00004, Rev. 3, May 26, 2011.

${ }^{* 7}$ T. L. Fellinger, “Testing for ARP/MCU Life Extension Project - DWPF," HLW-DWPF-TTR-2010-0045, November 18, 2010.

${ }^{* 8}$ J. D. Newell and D. K. Peeler, "Task Technical and Quality Assurance Plan for Evaluation of DWPF Impacts of Boric Acid Use in Cesium Strip for SWPF and MCU,” SRNL-RP-2010-01732, Rev. 2, May 2011.

9 D. L. Vien, N. B. Colthup, W. G. Fateley, and J. G. Grasselli, “ The Handbook of Infrared and Raman Characteristic Frequencies of Organic Molecules,” Academic Press, UK 1991.

10 R. Breslow, “Organic Reaction Mechanism; An Introduction,” W. A. Benjamin, California, 1969. 


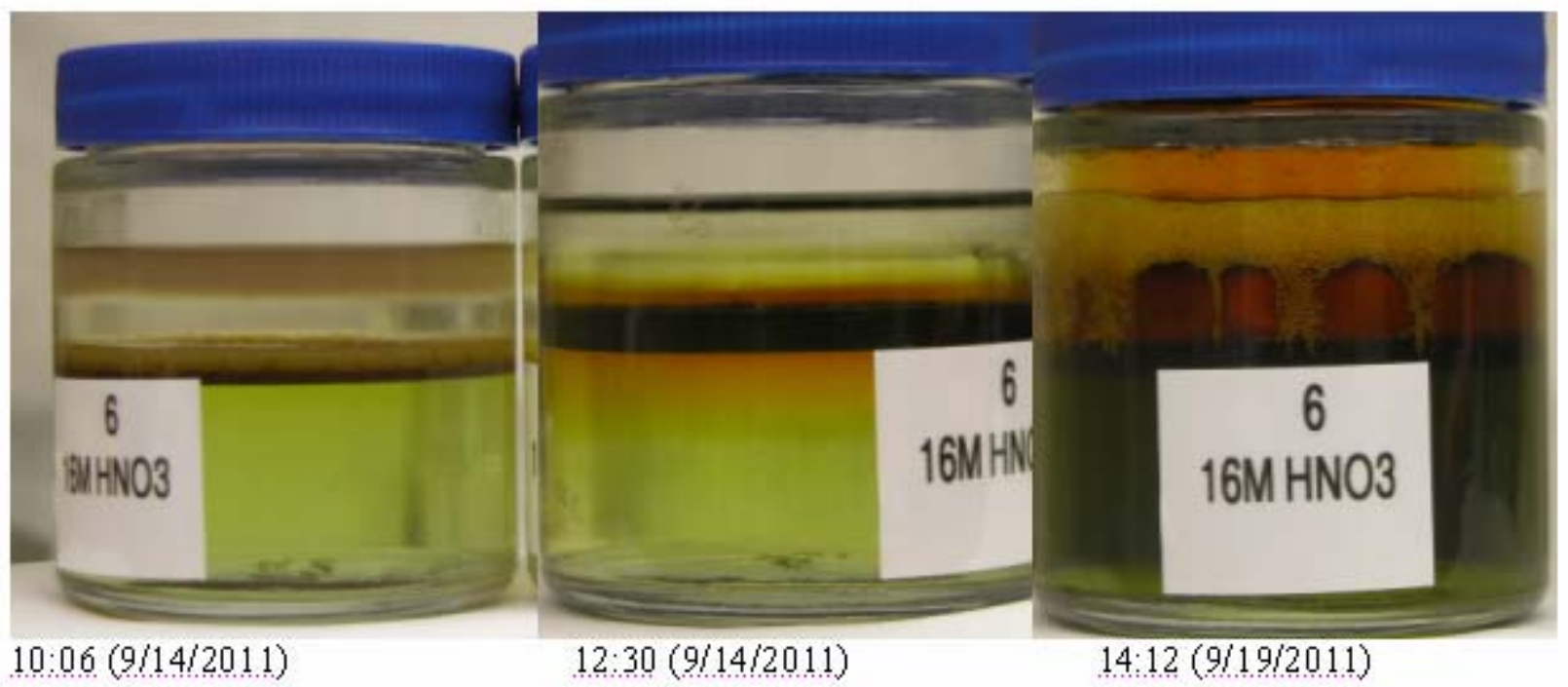

Fig. 3.4. A typical evolution in the chemical reaction between NGS and $16 \mathrm{M}$ nitric acid.

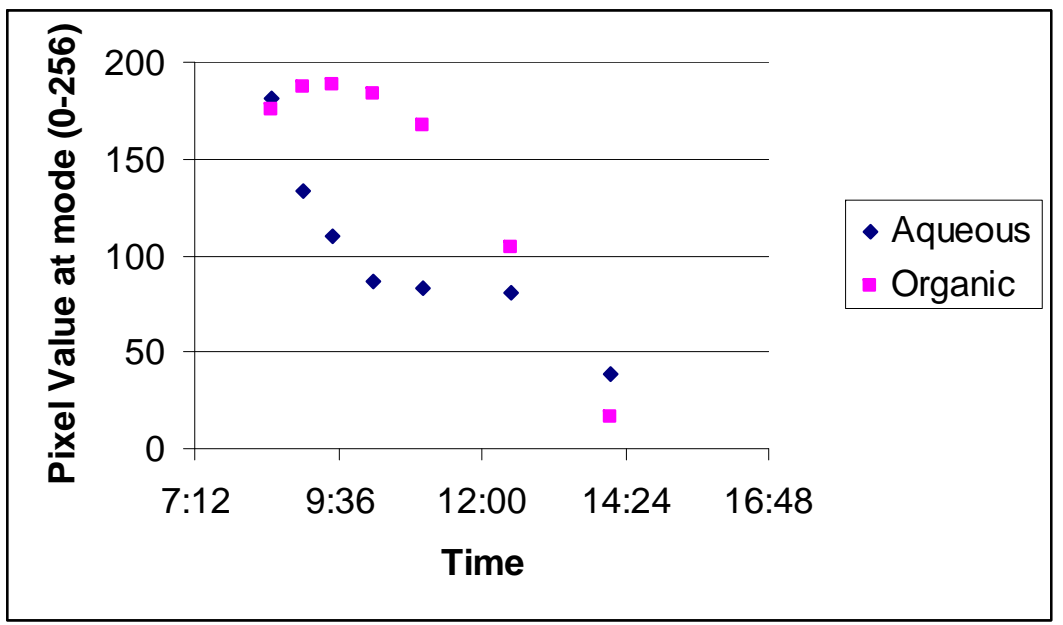

Fig. 3.5 A plot of the histogram mode for both aqueous (16 M nitric acid) and organic layer (NGS) as a function of time 

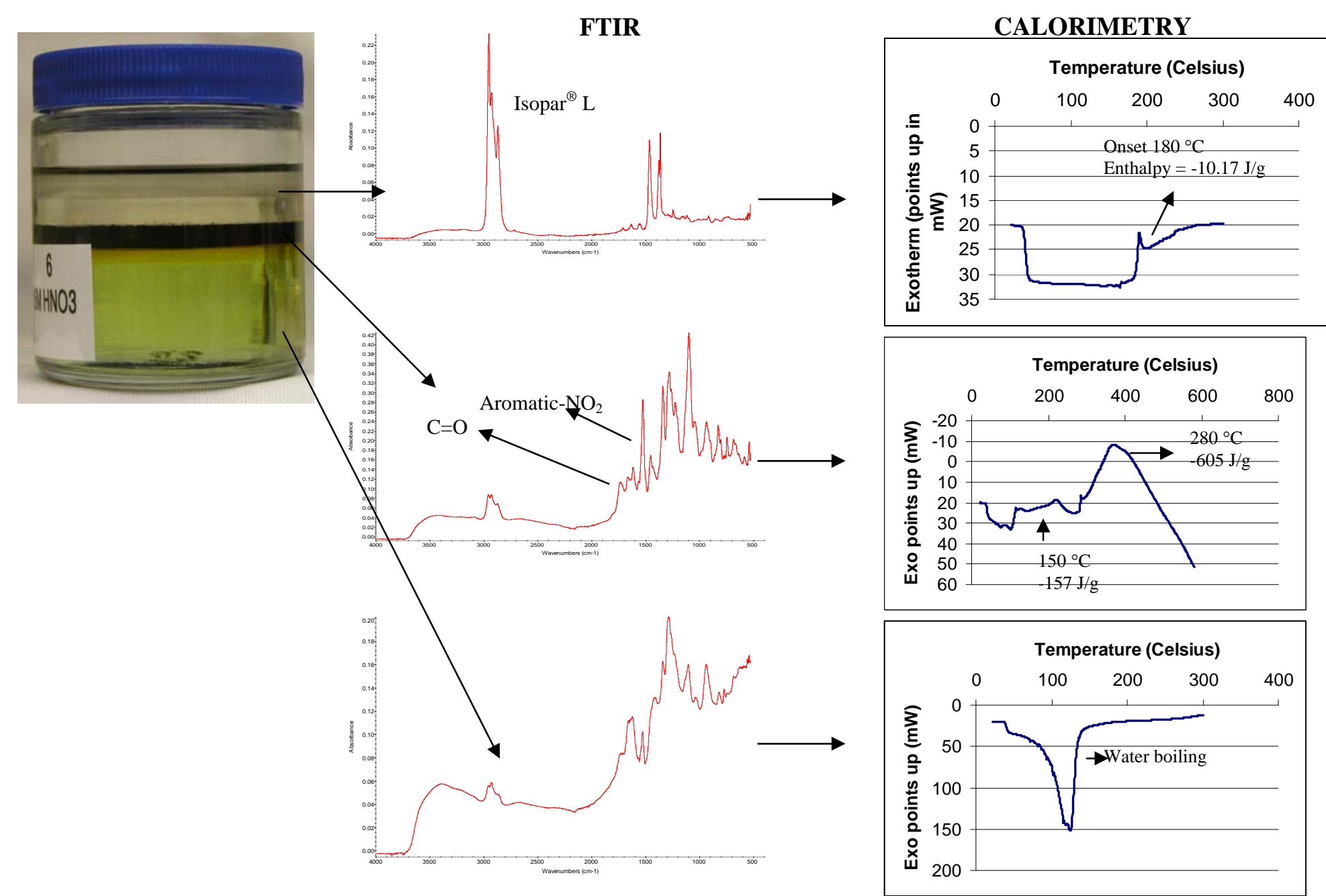

Figure 3.6. The energetic and chemistry of NGS after 4.5 hours in $16 \mathrm{M}$ nitric acid 


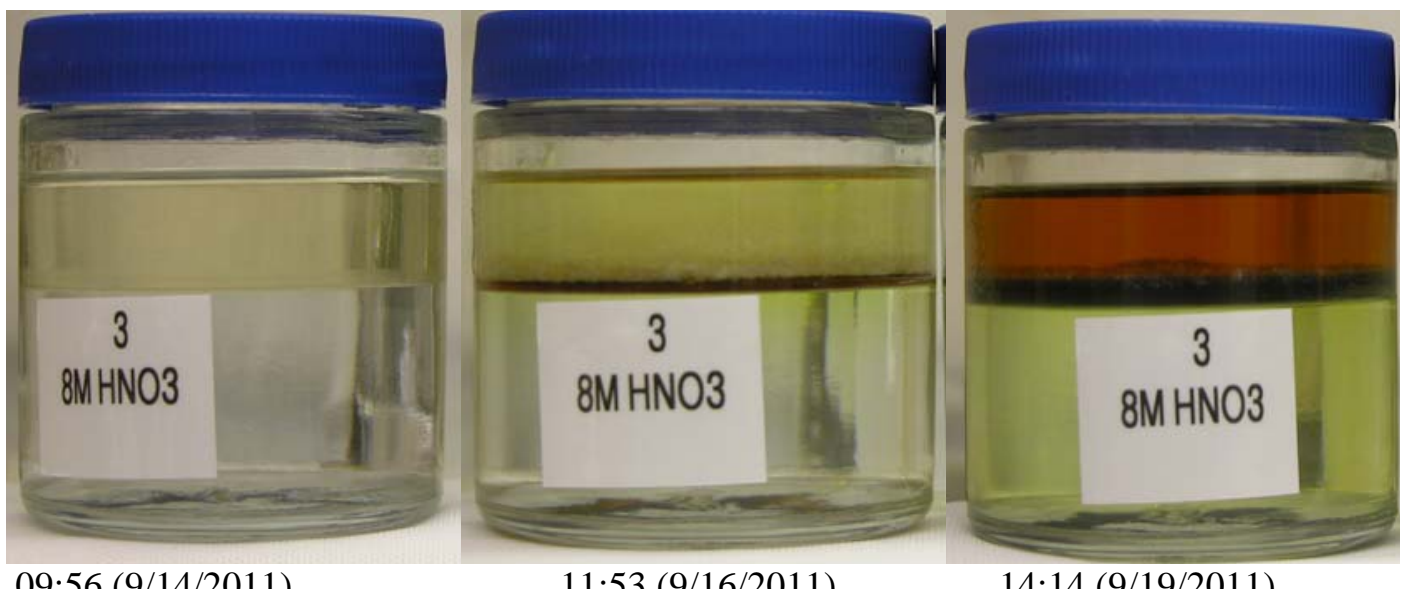

09:56 (9/14/2011)

$11: 53(9 / 16 / 2011)$

$14: 14(9 / 19 / 2011)$

Fig.3.7 Temporal evolution of NGS in $8 \mathrm{M}$ nitric acid

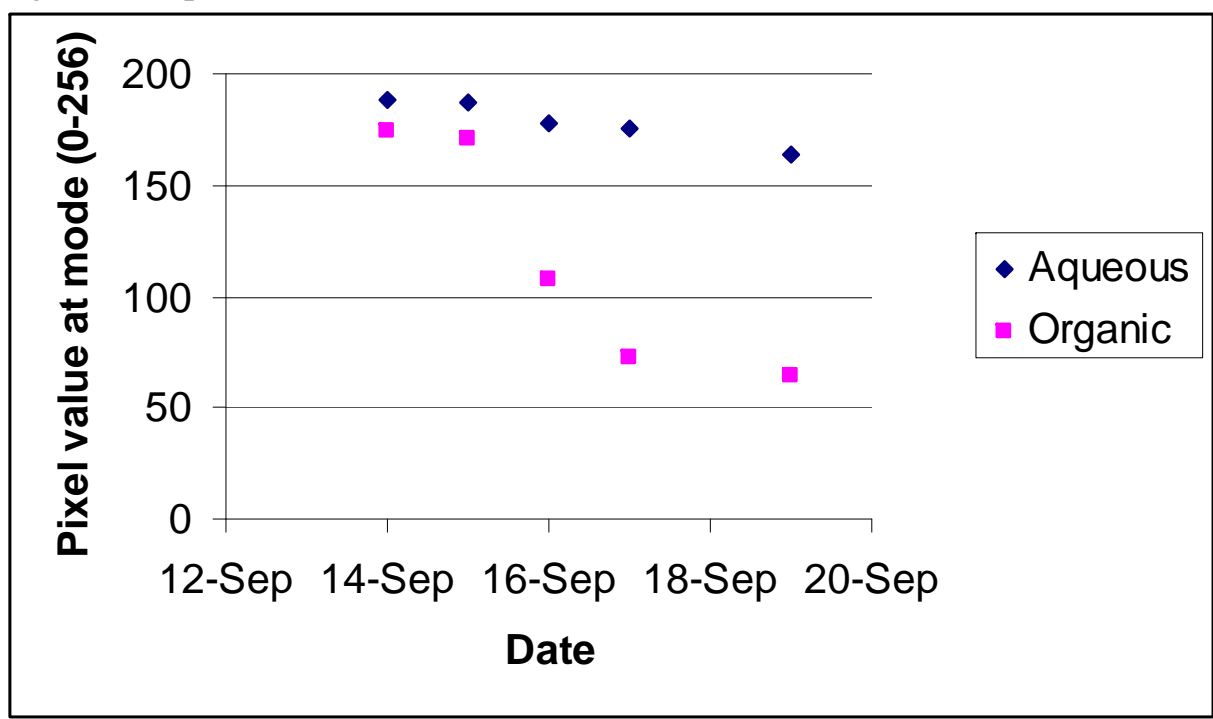

Fig. 3.8 The temporal evolution of the histogram mode for both aqueous (8 M nitric acid) and NGS 

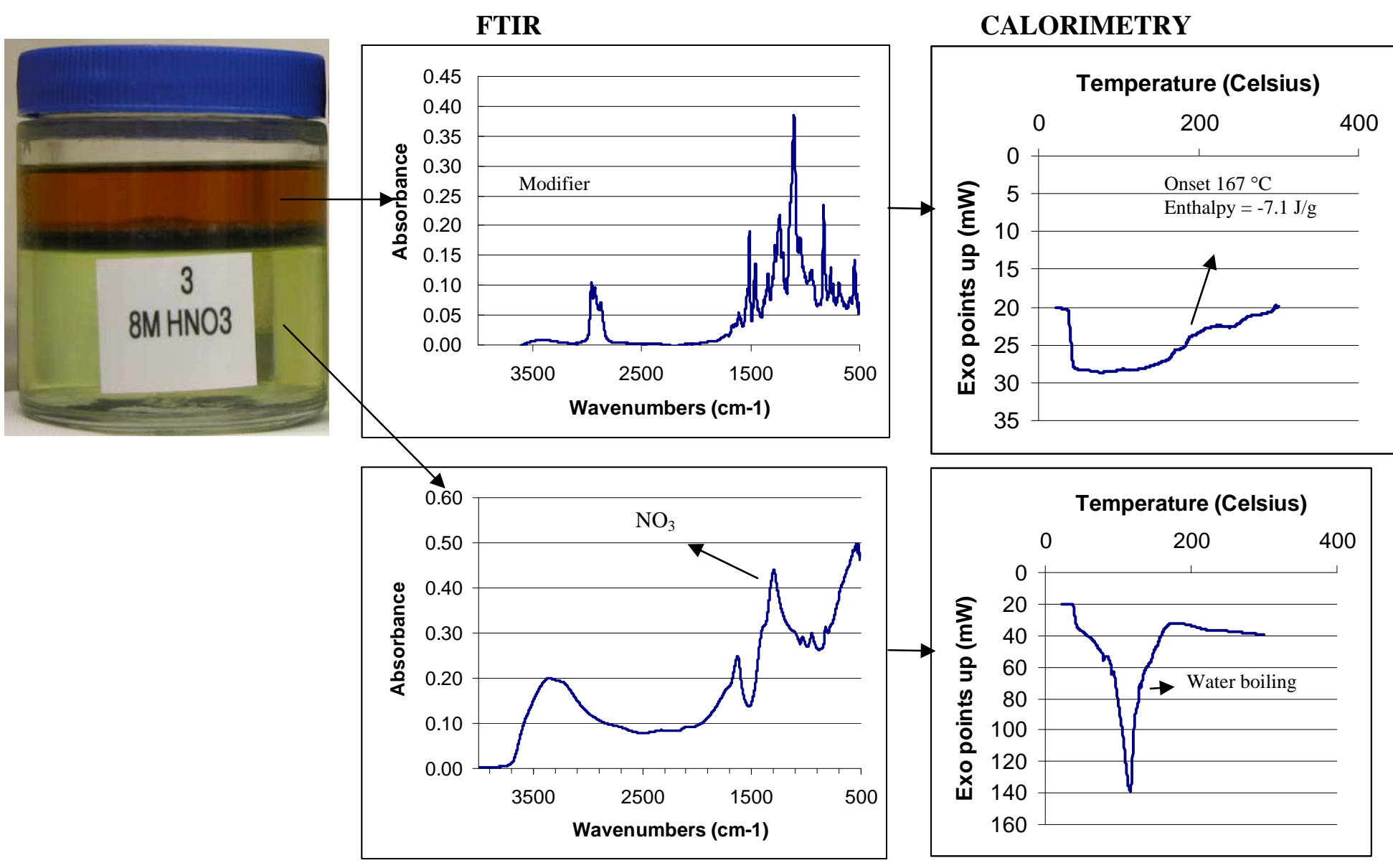

Figure 3.9. The energetic and chemistry of NGS after 120 hours in 8 M nitric acid 


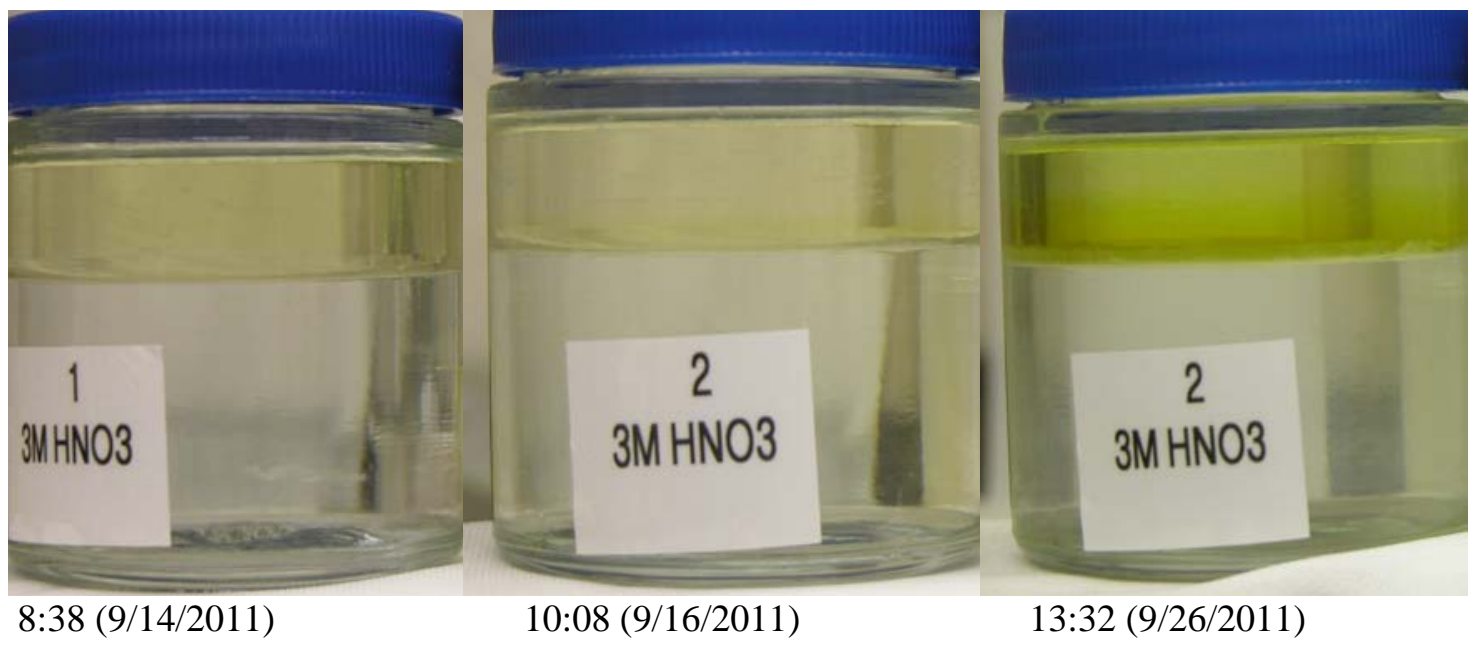

Fig. 3.10 The temporal evolution of NGS in $3 \mathrm{M}$ nitric acid. 


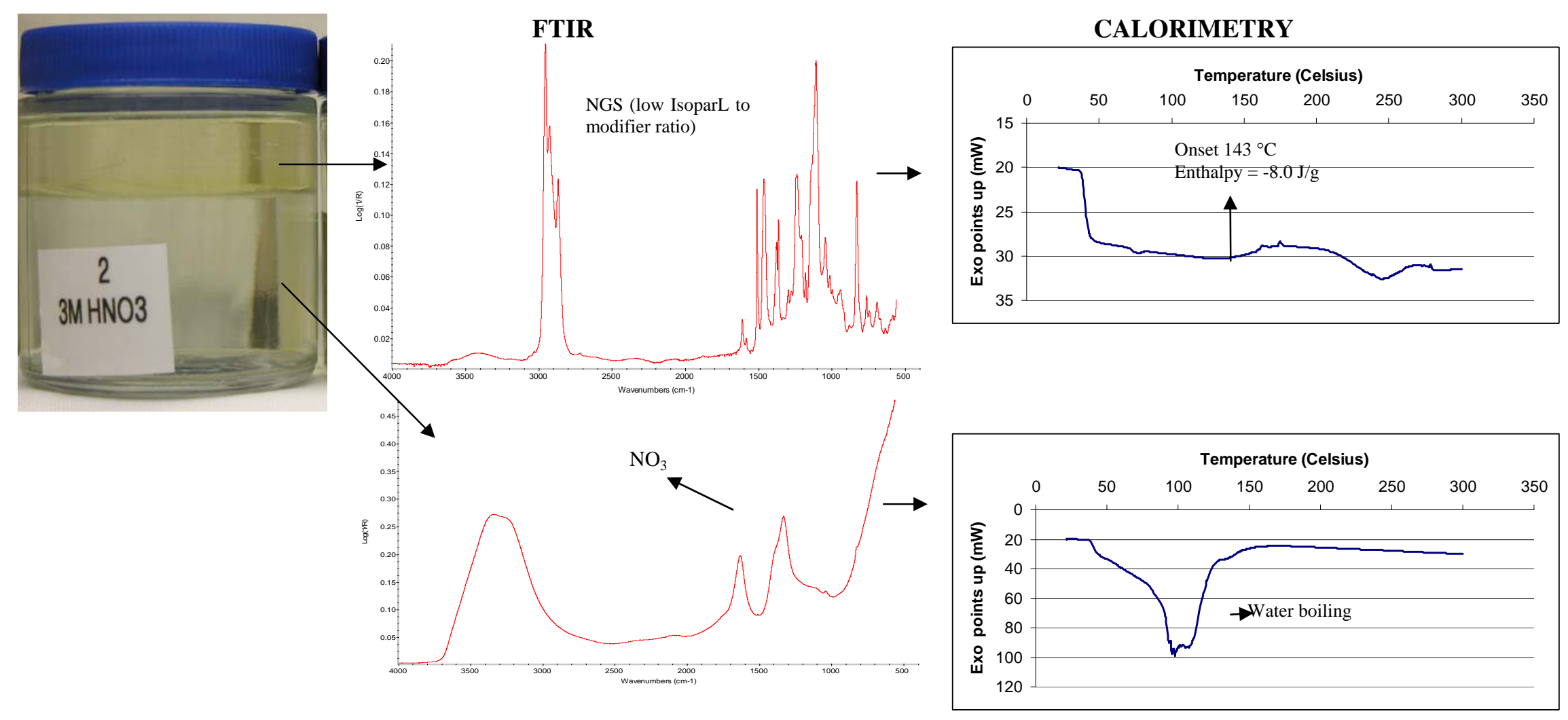

Figure 3.11. The energetic and chemistry of NGS after 48 hours in 3 M nitric acid 


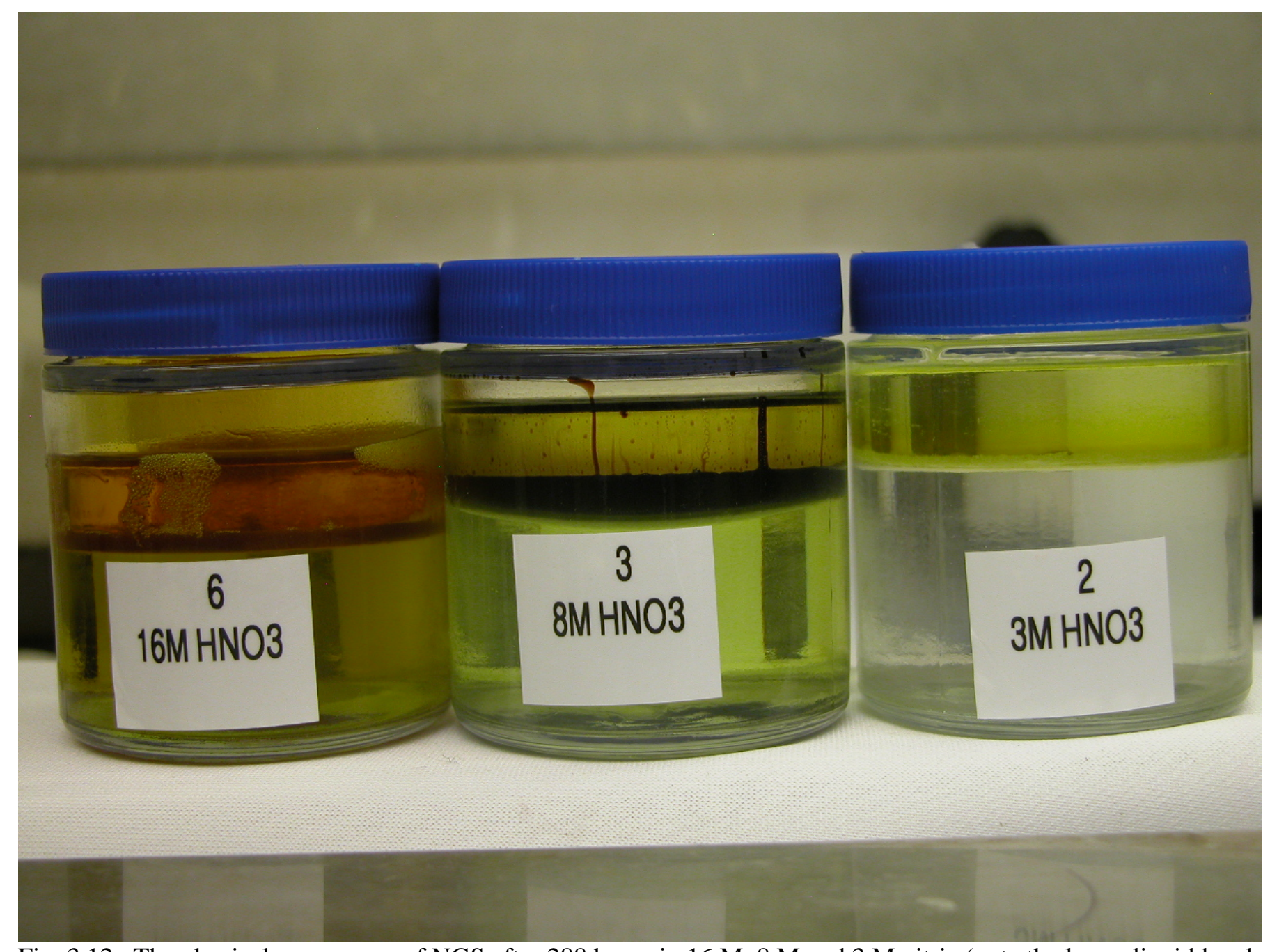

Fig. 3.12. The physical appearance of NGS after 288 hours in 16 M, 8 M and 3 M nitric (note the lower liquid level at higher nitric acid concentration). 


\section{Distribution:}
A. B. Barnes, 999-W
S. D. Fink, 773-A
B. J. Giddings, 786-5A
C. C. Herman, 999-W
S. L. Marra, 773-A
F. M. Pennebaker, 773-42A
W. R. Wilmarth, 773-A
J. C. Griffin, 773-A
T. B. Peters, 773-42A
R. A. Pierce, 773-A
F. F. Fondeur, 773-A
R. T. McNew, 704-27S
J. E. Occhipinti, 704-S
J. W. Ray, 704-S
H. B. Shah, 766-H
D. C. Sherburne, 704-S
R. E. Edwards, 773-67A
M. W. Geeting, 241-152H
B. A. Gifford, 704-56H
B. A. Oard, $241-197 \mathrm{H}$
A. Samadi, 241-197H
S. McLeskey, 241-152H
D. J. Martin, 241-152H
E. J. Freed, 704-56H

W. Brasel, 992-2W

C. Conner, Parsons

R. D. Lentsch, Parsons

M. S. Brugh, Parsons

T. D. Burns, Parsons

A. N. Singer, Parsons

M. J. Thomas, Parsons

R. J. Schepens, Parsons

R. K. Leugemors, 992-5W

P. G. Suggs, 704-S

B. A. Moyer, ORNL

L. Delmau, ORNL

J. Birdwell, ORNL

R. A. Leonard, ANL

P. Jackson, 703-46A 